\title{
SERUM MAGNESIUM AS A MARKER OF DIABETIC COMPLICATIONS
}

Dr Mirza Sharif Ahmed Baig1, Dr Mohd Shamshuddin² Dr K L Mahadevappa 3, Dr Abdul Hakeem Attar $^{1}$ Dr Abdul Kayyum Shaikh ${ }^{1}$

1. Department of Biochemistry, KBN Institute of Medical Sciences, Gulbarga.

2. Department of Biochemistry, Al Ameen Institute of medical Sciences, Bijapur.

3. Department of Biochemistry, KempeGowda Institute of Medical Sciences, Bangalore.

\section{CORRESPONDING AUTHOR:}

Dr Mirza Sharif Ahmed Baig,

Plot No. 109,

Macca Colony, Ring Road,

Gulbarga- 04,

Karnataka.

Email id- mirzasharifbaig@yahoo.in

Ph- 00919916039995

\begin{abstract}
:
Type 2 diabetes has become a leading cause of morbidity and mortality world over. Magnesium homeostasis has been hypothesized to be a link between insulin resistance type 2 diabetes mellitus, hypertension and CAD. This study was under taken to evaluate the relationship between serum magnesium and diabetes mellitus without and with complications. We found significantly low levels of serum magnesium in patients with DM when compared to control. Further significantly low levels of serum magnesium were found in patients with diabetic complications when compared with diabetic patients without complications. Hence it is concluded that the lower levels of serum magnesium may have a bearing on the complication and morbidity in patients of DM, and estimation of serum levels of magnesium may be helpful to monitor the severity of complications in diabetic patients.
\end{abstract}

KEY WORDS: Coronary Artery Disease, Diabetes Mellitus, Diabetic Retinopathy, Hypomagnesemia.

\section{INTRODUCTION:}

Magnesium, the fourth most common cation in the body, has been the recent focus of much clinical and scholarly interest. Previously underappreciated, this ion is now established as a central electrolyte in a large number of cellular metabolic reactions, including DNA and protein synthesis, neurotransmission, and hormone receptor binding. It is a component of GTPase and a cofactor for $\mathrm{Na}^{+} / \mathrm{K}^{+}$-ATPase, adenylate cyclase, and phosphofructokinase.

Magnesium is a cofactor in more than 300 cellular enzymatic systems and has a key role in cellular metabolism, the recognition that Mg deficiency or excess may be associated with significant clinical consequences has resulted in an increased interest in the utility of serum $\mathrm{Mg}$ measurement(1). Magnesium is an important intracellular cation that is distributed into three major compartments: mineral phase of bones (65\%), intracellular space (34\%) and extracellular fluid (1\%) (2). 
In several studies reduced magnesium concentrations have been observed in diabetic adults

The interrelationships between magnesium and carbohydrate metabolism have regained considerable interest over the last few years. The association between diabetes mellitus and hypomagnesaemia is compelling for its wide ranging impact on diabetic control and complications. Magnesium depletion has been linked to the development of retinopathy (8). The etiology of hypomagnesiamea cannt be clearly explained and serum magnesium levels have been shown to be inversely related to the severity of diabetes (9). Hypomagnesaemia has been linked to poor glycemic control, coronary artery diseases, hypertension, and diabetic neuropathy and foot ulcerations (10).

Hence this work was undertaken to evaluate the relationship between serum magnesium and diabetes mellitus without and with complications.

\section{MATERIAL AND METHODS:}

The present study was carried out in the Department of Biochemistry KBN Institute of Medical Sciences and KBNTGH Gulbarga, and KempeGowda Institute of Medical Sciences, Bangalore. Clearance was obtained from the institutional ethical committee.

The study was carried out on 30 age and sex matched healthy controls and 60 type 2 diabetic patients who attended the outpatient and inpatient department of KempeGowda Institute of Medical Sciences, Bangalore during the year 2007-2008.A total 60 patients of type 2 diabetes mellitus between 40 - 70 years, which were divided into following groups.

Control group: Included 30 healthy, age and sex matched individuals.

Group I: Included 30 patients of type 2 diabetes without complications.

Group II: Included 30 patients of type 2 diabetes with proven complications, like CAD, retinopathy and neuropathy.

The diagnosis of type 2 diabetes mellitus was established with the recommended criteria's of American diabetes Association.

Inclusion Criteria: Patients in the age group of 40-70 years with type 2 diabetes without and with proven complications, like CAD, neuropathy and retinopathy were selected.

Exclusion Criteria: Patients with recent infectious disease, immunological disorders, taking diuretics and magnesium containing antacids, malabsorption syndrome, chronic diarrhea, renal failure, pancreatitis, alcoholism, liver diseases, tuberculosis and thyrotoxicosis were excluded from the study.

Informed consent was taken from patient and control subjects. A pre-structured and pretested proforma was used to collect the data. Baseline data including age and sex, detailed medical history including conventional risk factors, clinical examinations and relevant investigations including ECG, echocardiogram, nerve conduction test, fundoscopy etc were included as part of the methodology.

Fasting venous blood samples were collected from cases and controls and the samples were centrifuged, serum was separated and stored at $4^{\circ} \mathrm{C}$. Serum magnesium was estimated by Calmagite dye method (11) by using auto-analyzer $\left(\mathrm{A}_{25}\right.$ Biosystem). Magnesium reacts with the blue dye, calmagite, in alkaline medium to form red colored complex which is measured at $530-550 \mathrm{~nm}$. The intensity of the color formed is directly proportional to the amount of magnesium in the sample. 
Protein interference and dye precipitation are avoided including the 9-ethylene oxide adduct of pnonylphenol (Bion NE9) and Polyvinyl pyrrolidone (Bion pup). Calcium interference is avoided by preferential combination with EDTA and heavy metal interference is prevented by Potassium cyanide. The reference range for serum magnesium concentration does not vary significantly for age or sex and is closely maintained within a range of $1.7-2.4 \mathrm{mg} / \mathrm{dl}$.

PPBS were estimated 2 hours after breakfast. Urine sample was analyzed for protein and sugar.

\section{STATISTICAL METHODS:}

Student ' $t$ ' test /Chi-square test has been used to find the significance of homogeneity of study characteristics between three groups of patients. Analysis of variance has been used to find the significance of study parameters between three groups. Results were expressed as mean \pm SD. Probability values of $\mathrm{P}<0.05$ were considered to indicate statistical significance.

\section{STATISTICAL SOFTWARE:}

SPSS 15.0, Stata 8.0, MedCalc 9.0.1 and Systat 11.0 were used for the analysis of the data and Microsoft word and Excel have been used to generate graphs, tables etc.

\section{RESULTS:}

Results of the present study showed significant low values of serum magnesium $(\mathrm{P}<0.001)$ in patients of DM without complications when compared with controls. Further significant low values of serum mg $(\mathrm{P}<0.001)$ were found in patients of DM (Table 1 \& Fig 1 ) with complications when compared with control.

\section{DISCUSSION:}

The magnesium ion has been shown to play an important role in the metabolism of carbohydrates by activating various enzyme systems and helping insulin for its action. In this study it was observed that the mean serum magnesium level was statistically significantly low $(\mathrm{P}<0.001)$ in Diabetic patients without and with complications when compared with controls. This indicates the association of hypomagnesaemia with diabetes mellitus. These results are in accordance with the observation of Tosiello L (12), Kao WH (13), and Chamber E C (14). In our study, serum magnesium level in cases with diabetic complications $(1.29 \pm 0.31)$ was much lower than those without complications $(1.61 \pm 0.41)$.

We also noted that in subjects with diabetic complications serum magnesium levels were much lower when compared to diabetics without complications. Hatwal A et al, Andrea Corsenello et al and Rodriguez Moran $\mathrm{M}$ et al have found similar results in patients with diabetic complications. Ishrath Kareem et al found that serum magnesium levels in patients with diabetic retinopathy were significantly lowered compared to patients without retinopathy (15). Aradhana Sharma et al also found that serum magnesium levels were significantly lowered in patients with diabetic complications when compared to diabetic patients without complications (16).

In our opinion the release of insulin caused by a glucose challenge is partly dependent on adequate magnesium. Insulin, via its interaction with ligand activated tyrosine protein kinase associated receptors, initiates a cascade of biochemical interactions that result in several 
physiological, biochemical and molecular events that are involved in carbohydrate, lipid and protein metabolism (17). Although the binding of insulin to its receptor does not appear to be altered by magnesium status, the ability of insulin once bound to receptor to activate tyrosine kinase is reduced in hypomagnesaemia states (18). As a result reduced peripheral glucose uptake and oxidation are often noted in subjects with hypomagnesaemia. Decrements in the enzymatic activities of several metabolic pathways are seen in DM patients as a result of the relative magnesium deficiency (19).

The exact cause of diabetic hypomagnesaemia is still unknown but an increased urinary loss of magnesium may contribute to it. Hypomagnesaemia has been reported to occur at an increased frequency among patients with type 2 diabetes compared with their counter parts without diabetes. Despite numerous reports linking hypomagnesaemia to chronic diabetic complications, attention to this issue is poor among clinicians. The precise mechanism for development of microvascular changes is not fully understood, it is possible that hypomagnesaemia inhibits prostacyclin receptor function producing an imbalance between prostacyclin and thromboxane effect which has marked atherogenic potential which is responsible for microvascular complications.

Thus we conclude that the estimation of serum magnesium levels is helpful to monitor the severity of complications in type 2 diabetes and also be useful for proper medical intervention.

Hence further studies on serum magnesium levels and on oral supplementation to prevent late complications of diabetes will be interesting and helpful.

Table 1: Serum Magnesium in the three study groups

\begin{tabular}{|l|l|l|l|}
\hline $\begin{array}{l}\text { Study } \\
\text { parameters }\end{array}$ & Controls & $\begin{array}{l}\text { DM without } \\
\text { complications }\end{array}$ & $\begin{array}{l}\text { DM with } \\
\text { Complications }\end{array}$ \\
\hline Sr.Mg /dl & $2.17 \pm 0.35$ & $1.61 \pm 0.41^{* *}$ & $1.29 \pm 0.31^{* *}$ \\
\hline
\end{tabular}

Fig 1: Serum Magnesium in the three study groups

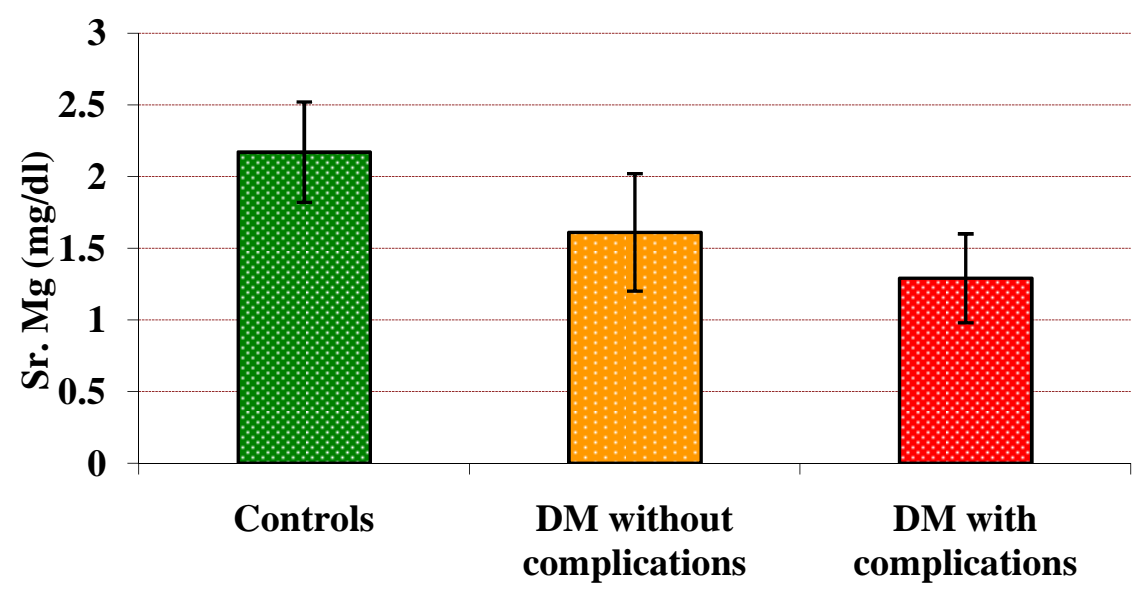

Journal of Evolution of Medical and Dental Sciences/ Volume 1/ Issue 3/ July-Sept 2012 


\section{REFERENCES:}

1. Elin R. J.Assement of magnesium status. Clin Chem 1987; 33:1965 - 1970.

2. Gums J G. Clinical significance of magnesium: A review. Drug Intell Clin Pharm 1987; 21: $240-246$.

3. Maltezos E,Papazoglou D, Exiara T, Kambouromiti G, Antonoglou C. Serum magnesium levels in non diabetic offspring of patients with type 2 diabetes mellitus. Diabetes Nutr Metab 2004; 17:12 - 16.

4. Mc Nair P, Christiansen C, Madshad S. Hypomagnesaemia a risk factor in diabetic retinopathy. Diabetes 1978; 27:961 - 965.

5. Mather H M, Nisbet J A, Bruton G H. Hypomagnesaemia in diabetes. Clin Chem Acta 1979; 95:235 - 242.

6. Fuji S, Tekemura $\mathrm{T}$, Wada $\mathrm{M}$, Akai $\mathrm{T}$, Okurr $\mathrm{k} \mathrm{m}$. Magnesium levels in plasma , erythrocyte and urine in patients with diabetes mellitus. Horn Metab Res 1982; 14: 161 $-162$.

7. Johansson G, Danielsson B G, Ljunghalls, Wibell L. Evidence for a disturbed magnesium metabolism in diabetes mellitus. Magnesium 1982; 3:178 - 180.

8. Ceriella A, Giugliano D, Dellorurso P, Passariello. Hypomagnesaemia in relation to diabetic retinopathy. Diabetic Care. 1982; 5:558 - 559.

9. Hamid Nasri, Hamid Raza Baradaran. Lipids in association with serum magnesium in diabetes mellitus patients. Bratisl Lek Listy.2008;109(7):302-306

10. Pham PC, Pham PM, Pham SV et al .Hypomagnesaemia in patients with type 2 diabetes .Clin Am Soc Nephrol 2007;2:366-73.

11. Gindler EM, Heth DA. Colorimeter determination with bound "Calmagite" of magnesium in human blood serum. Clin Chem 1971; 17:662.

12. Tosiello L. Hypomagnesaemia and diabetes mellitus. A review of clinical implications. Arch Intern Med 1996; 156(1):1143 - 1148.

13. Kao W H. Serum and dietary magnesium and the risk for type 2 diabetes mellitus. The Atherosclerosis risk in communities study. Arch Intern Med 1999; 159(8):2151 - 2159.

14. Chambers EC, Heshkas, Gallagherd.Serum magnesium and type 2 diabetes in African Americans and Hispanics a Newyork Cohort. J Am Coll Nutr. 2006; 25:509 - 513.

15. Ishrat Kareem, Jaweed SA. Bardapurkar JS et al. Study of magnesium, glycosylated hemoglobin and lipid profile in diabetic retinopathy. Indian Journal of Clinical Biochemistry, 2004; 19(2);124-127.

16. Aradhana Sharma, Surekha Dabla, RP Agarwal et al. Serum magnesium; An early predictor of course and complications of diabetes mellitus. J Indian Med Assoc 2007;105:16-20.

17. Lefebvre P J, Scheen A J. Improving the action of insulin. Clin Invest Med 1995; 18:342 347.

18. Suarez A. Decreased insulin sensitivity in skeletal muscle of hypomagnesaemia rats. Diabetologia 1993; 36:A82.

19. Laughlin M R, Thompson D. The regulatory rule for magnesium in glycolytic flux of the human erythrocyte. J Biol Chem 1996; 271: 28977 - 83. 